Volume 8. No. 9, September 2020

International Journal of Emerging Trends in Engineering Research

Available Online at http://www.warse.org/IJETER/static/pdf/file/ijeter267892020.pdf

https://doi.org/10.30534/ijeter/2020/267892020

\title{
Providing the Development of New Designs for the Design of the Roller Mechanism Transmitting Rotational Motion in Belt Conveyors
}

\author{
Anvar Djuraev ${ }^{1}$, Akbarjon Jumaev ${ }^{2}$ \\ ${ }^{1}$ Department of General Technical Disciplines, Tashkent Institute of Textile and Light Industry, Tashkent, \\ Uzbekistan, ziyokor5@gmail.com \\ ${ }^{2}$ Navoi branch of the Academy of Sciences of the Republic of Uzbekistan, Navoi, Uzbekistan.
}

\begin{abstract}
The article proposes to use a plastic and composite material of a flexible element, which acts as sliding support instead of a detailed rolling bearing, which provides a smooth rotational movement of the guide roller mechanism, which performs the rotational movement of the conveyor belt. At the same time, the details of the projected mechanism (guide roller) were drawn from the relatively light, high-strength plastic and composite material of the flexible element and their structural drawings. Graphitocaprolon is a relatively rigid material, but for the sake of fragility, we wear a sleeve of a flexible element with an external coating on the part (graphitocaprolon) to prevent cracking as a result of external impacts on the roller mechanism. As a result, it is concluded that the period of periodic operation is longer, while the part, acting as a sliding base, is protected from external shocks during operation.
\end{abstract}

Key words: Mechanism, Bearing, Conveyor, Hinge, Rolling, Elastic, Graphite Capralon, Kinematics, Roller, Support, Technology.

\section{INTRODUCTION}

Mining companies conduct extensive research with the aim of creating new designs of conveyor belts that meet modern requirements, developing methods of structural, kinematic and dynamic analysis to justify their parameters, as well as creating methods and technologies that ensure high-quality performance of mechanical engineering processes. In this direction, including in the mining industry, the development of belt conveyors with high efficiency and manufacturability is of great importance. At the same time, in order to optimize the regime and performance of mining equipment, including improving the quality of conveyor belts, it is necessary to develop working bodies of guide roller mechanisms and new designs of transmission mechanisms [1].

Today, when the depth of quarries in the world increases to $1000 \mathrm{~m}$, cars are becoming more important, which is an average of $50-70 \%$ of the cost of production. They provide uninterrupted movement of minerals over long distances; have high performance, reliability, energy consumption and durability [2].

The production of vehicles of a new technical level and the use of innovative design stages will reduce transport costs, reduce the negative impact of vehicles on the environment, reduce transportation costs and increase operational safety. One of the vehicles is a conveyor belt, which will increase the efficiency of mining by $25-30 \%$ and increase these figures with the deepening of quarries [3].

\section{MATERIALS AND METHODS}

Belt conveyors are transport machines, the main work is a roller mechanism with slave control and flexible tapes. Conveyor lines are used in all areas of the mining and metallurgical industries, agriculture and production for the transportation of bulk and piece goods over short, medium and long distances. An important advantage of the belt conveyor is that when transporting up to 20.000 tons of product per hour from one place to another at high speeds (6$8 \mathrm{~m} / \mathrm{s}$ ) and depending on the width of the belt, the work efficiency is several times higher than for other types transport nodes. It is characterized by simplicity of design and operation, simplicity of operation and automation of control, high reliability of the mechanism of guide rollers even when working in heavy industry [4].

At the same time, mainly in the mining and metallurgical industries, as a result of the presence of a constant load, dust, humidity and temperature, the bearings of the guide roller mechanisms harden. As a result, the fact that the total power of the drive motors reaches $10000 \mathrm{~kW}$ and the high friction of the belt remains one of the main disadvantages of belt conveyors [5].

This means that these guide roller mechanisms remain the main part of the working defect in the conveyor belt. To do this, we ensure the continuous operation of the mechanism, using parts that act as a sliding base instead of the bearing, which provides a smooth rotational movement of the guide roller mechanism without damaging all parts of the conveyor. Today in the manufacturing industry, economic efficiency is achieved by creating relatively light machine mechanisms using high-strength flexible elements and plastic materials instead of metal. 


\subsection{Operating conditions for conveyor belts in mining enterprises}

The conveyor belts used in mining enterprises are characterized by constant operating conditions, i.e. constant humidity and dust. As a result of the constant high chemical activity of water in underground mines, constant dust, sand particles and sediments during heating of reserves in an open pit, the mechanism of the guide roller of the conveyor belt can enter the body parts, making a smooth rotational movement, and subsequently affect the quality of the products. In addition, an increase in relative humidity by $86-90 \%$ as a result of the ambient temperature at the place of use of the equipment from minus 25 to $30^{\circ} \mathrm{C}$ will inevitably affect the frequency of operation of the equipment [6].

The formation of moisture in oil products is gradually affected by the components of the roller mechanism, which leads to corrosion of parts. Cracks are formed as a result of the constant ingress of dust and abrasive particles into the protective casing and bullet during operation. This situation also affects parts that act as a slowly sliding base. All these conditions lead to a decrease in the operating frequency of the mechanisms of the guide rollers, which leads to repair before the expiration of the specified service life, and then this condition causes the entire conveyor belt to stop.

Today, providing the mining industry with modern equipment has a significant impact on operational efficiency. The industry uses parts of modern and various types of belt conveyors (belt, guide roller and drum). Depending on the conditions of use, various types of protective covers for roller guides can be used. This, in turn, significantly prevents the ingress of dust and moisture into parts that act as a sliding base, and also reduces the negative impact of changes in the internal structure of oil products [7].

In the mining industry, there are cases of rapid failure of the roller mechanisms of conveyor belts due to external influences. Currently, it is observed that the service life of belt conveyors developed in domestic and foreign countries with the same operating conditions differs from each other. That is, the service life of roller mechanisms of domestic belt conveyors is 2-3 times shorter than that of roller mechanisms manufactured in foreign countries: up to 1.5 years less in underground mines and up to 2 years in quarries. One of the reasons for this is that the choice of lubricants depending on operating conditions and the temperature of the conveyor belts depends on the specific operating conditions [8].

One of the main factors determining the frequency of operation and the durability of the roller mechanisms is the ambient temperature. As a result of the conveyor's operation at high temperatures, the viscosity of the lubricant is lost, and at the same time, the ability of the product to seal is deteriorated. On the contrary, in mechanisms operating at low temperatures, the viscosity, lubrication and plasticity of lubricating products increase. As a result, the lubricating properties of the oil material are reduced, which leads to an increase in the resistance to rotation of roller conveyor mechanisms and the difficulty of starting belt conveyors [9]. Increased resistance to rotation of the guide roller mechanisms is one of the main factors in reducing the operational characteristics of belt conveyors.

It is recommended to identify factors affecting the performance of belt conveyors, i.e. determine the availability factor of the mechanism according to the following formula.

$$
K=\frac{K_{g}}{K_{g}+n\left(1-K_{g}\right)}
$$

where $K_{g}$ is the coefficient of preparation of the conveyor belt; $\mathrm{n}$ is the number of conveyors in the production line, pieces; According to the data obtained, the coefficient of preparation of the conveyor belt for abrasive ore masses of rocks is $K_{g}==0.72-0.92$

Factors to the actual source of the conveyor belt the main reasons for the failure of the conveyor during transportation of rock mass are:

- stops due to mechanical malfunctions: repair of the guide roller mechanism, failure of the mechanical part, gearbox repair, voltage station repair, brake repair, oil section repair; - malfunctions due to electrical equipment: malfunctions of electrical parts, lack of power supply, failure of current protection devices, damage to control devices;

- planned outages: inspection of equipment and maintenance;

- other downtimes: failure of the crusher and other interconnected equipment, cleaning of the ore mass, lack of ore, ore leakage and others

It turned out that the study and processing of failures during transportation of ore in the mining quarries of the republic and the collection of data during the operation of conveyors in foreign mining quarries allow us to establish a relationship between the causes of failure of the conveyor (Fig.1).

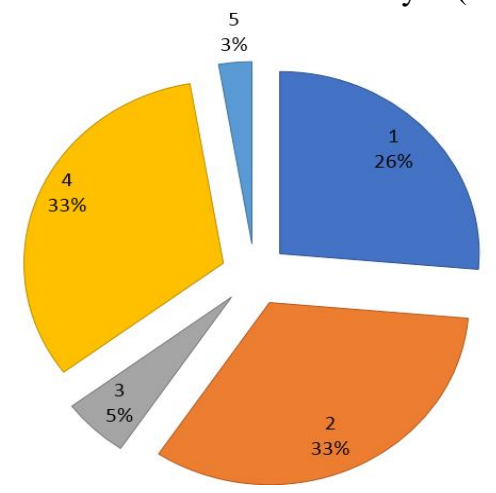

1 - Failure of the mechanical part;

2 - Damage to the guide roller mechanisms;

3 - Malfunctions in the electrical part;

4 - Equipment check during scheduled and scheduled repairs;

5 - Random reasons.

Figure 1: The ratio of the reasons for stopping the conveyor belt 
Apparently, one of the main reasons for the failure of the conveyor belt is the failure of the mechanisms of the guide rollers, which accounted for $33 \%$ of the total number of stopped conveyor lines.

\subsection{Structural analysis and structural design of parts by guide rollers of belt conveyors}

One of the key components of the conveyor belt, which determines the efficiency of the conveyor belt and especially the service life of the belt, are these mechanisms of the guide rollers. The nature of the load (with or without impact) on the durability and reliability of the roller conveyor mechanisms; physical and mechanical properties of the cargo; development of a new design of parts of the guide roller mechanism; factors such as conditions of use.

Depending on the operating conditions, several types of belt conveyors have been developed: which are designed in accordance with the following characteristics: conveyor slope; by type of conveyor line (straight or curved); by type of tape (width and length); by the number of guide roller mechanisms; according to the location of the guide roller mechanism (angle and distance); by type of cargo; in accordance with the location of the carrier network of the belt; cross-sectional shape of the carrier network of the belt.

The main components of belt conveyors are a guide roller mechanism, a guide drum and a belt surrounding them. (Fig.2). The conveyor also includes the following parts: devices for compressing and cleaning the tape, handles, special roller mechanisms, elements that provide automatic control and movement of the tape [10].

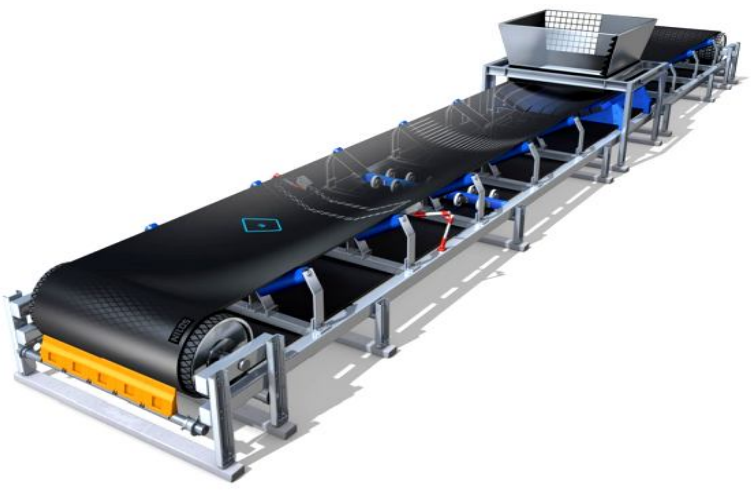

Figure 2: Belt Conveyor

The guide roller mechanism performs two different functions on a conveyor belt: for transporting cargo; conveyor guiding roller mechanisms will be installed to hold the belt in an empty network. In mining plants, the mechanisms of the guide rollers on the belt line are located at the same distance, and the bending angle of the side rollers at 200, 300, 360, 450 degrees relative to each other of the three rollers in each interval consists of the mechanisms of the guide rollers of the same length (Fig.3).

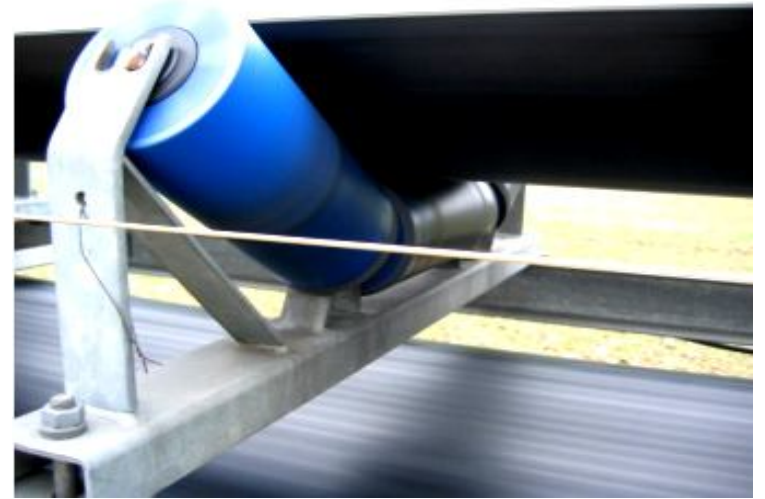

Figure 3: Guide Roller (Conveyor Belt)

Depending on the operating conditions of the conveyor belt, the mechanisms of the guide rollers are usually divided into light, medium and heavy series. Heavy underground conveyor roller mechanisms are often used in underground mines and quarries. This is due to the fact that the heavy-duty guide roller mechanism is a reliable mechanism from the point of view of design that can withstand heavy loads. The main difference between the mechanisms of the guide rollers is that they are divided depending on the level of protection of the protective caps used to protect the bearing from the external environment (dust, moisture and abrasive particles) (Fig.4).

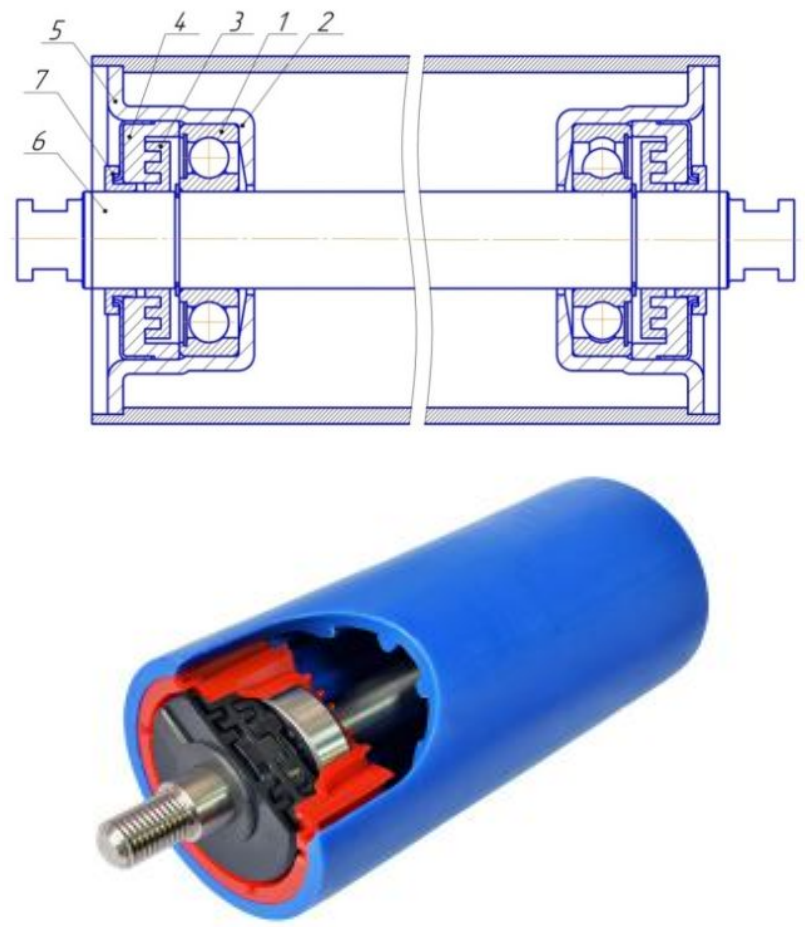

1-rolling bearing, 2- stupitsa, 3- Labyrinth cover ${ }^{1}$, 4Labyrinth cover ${ }^{2}, 5$ - cover, 6- bullet, 7- labyrinth cover

Figure 4: Guide Roller Mechanism (Conveyor Belt)

As mentioned above, in the design of the mechanisms of the guide rollers: special greased sandpaper, a set of labyrinth covers, contact and rubber protective coatings of the sleeves are used in the mechanism of the guide rollers to protect the 
bearing from the external environment (dust, moisture and abrasive particles). Depending on the operating conditions of the conveyor belt, these protective devices are used, and during operation it is confirmed that they also have a number of advantages and disadvantages. As a rule, the protective caps of the guide roller mechanism can be divided into contact, non-contact or slotted and combined parts [11].

In the mining industry, conveyor roller mechanisms of belt conveyors are part of bearings that perform a smooth rotational movement. Frequency and durability of conveyor mechanisms are important, as the equipment is determined depending on the installed workplace and temperature. Permanent dust and abrasive sand particles in quarries and a constant increase in humidity in underground mines will inevitably have a negative effect on the details of the guide roller mechanism. For example, in bearings providing a smooth rotational movement in the mechanism, the outer and inner rings of the part arise as a result of external influences. In turn, there are cases of stiffness of the bearings, as a result of which the guide roller mechanism stops rotating. This situation also affects other parts of the conveyor. For example, friction of belts increases the conveyor's resistance to rotation and the risk of equipment failure [12].

Extensive research is carried out to create a new design of belt conveyors and parts, synthesis, development of methods of structural, kinematic and dynamic analysis to substantiate the parameters and methods and technologies to ensure high-quality performance of production processes in the mining industry [13]. In this direction, the development of belt conveyors and their parts with high efficiency and manufacturability is of great importance. At the same time, in order to optimize the mode and performance of mining equipment, including improving the quality of belt conveyors, it is necessary to develop working bodies of guide roller mechanisms and new designs of transmission mechanisms.

The structural design of the roller mechanisms of the conveyor belt involves a radical change in its parts. It should be noted that today the design of machines includes the production of quality products that are relatively compact, lightweight and very durable [14].

To prevent the aforementioned cases, it is recommended to use the sliding support function using high-strength plastic (graphitecaprolon) and composite flexible materials instead of bearings that perform flat circular motions in the roller conveyor belt mechanism.

For this, several types of structures have been developed that act as a sliding base. On the inner surface of the part, which acts as a sliding support, two trapezoidal grooves open in a circle (Fig. 5). Appointment: the mechanism reduces friction at start-up; reduces the coefficient of friction of oil products between the bullet and the part; high efficiency; compact overall dimensions in the axial direction; makes it easy to replace and maintain parts [15].

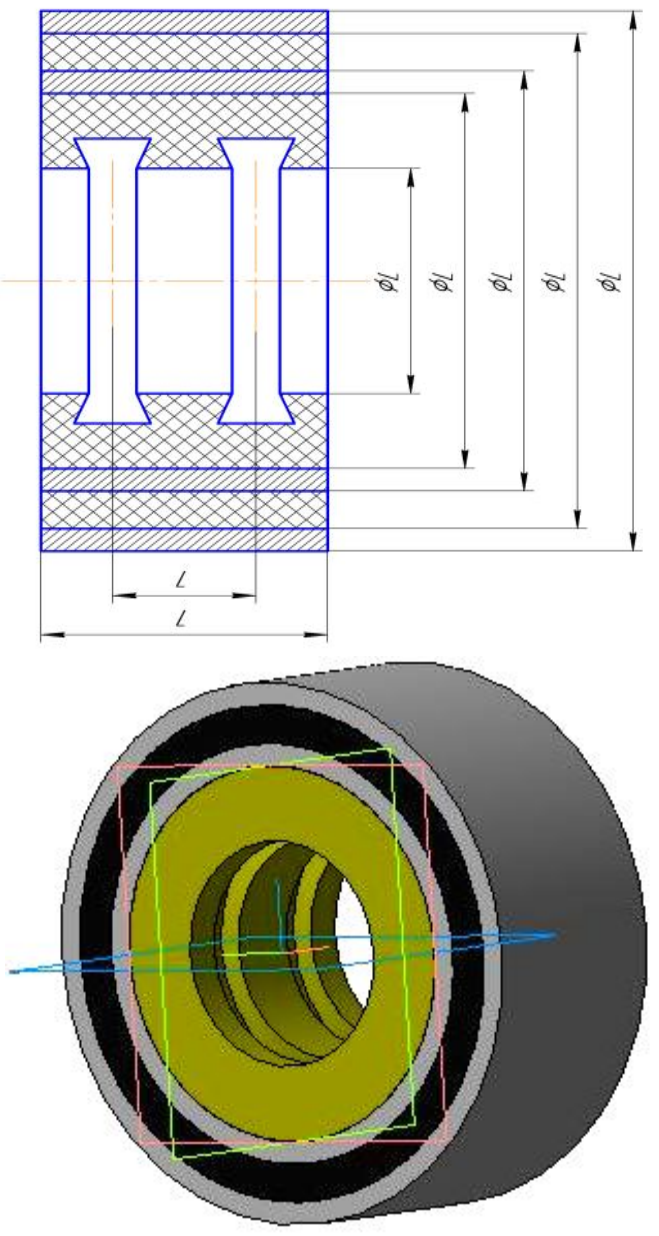

Figure 5: Sliding Support (Roller mechanism)

When designing the design of a part that acts as a sliding base, its effectiveness, the accuracy of calculating the surface of parts taking into account the current load, type of lubrication and operating conditions are largely taken into account. One of the main reasons for the failure of a part, which acts as a sliding support mounted on the mechanism of the guide roller, is the erosion of friction surfaces (inner surface) as a result of constant and variable exposure to the weight of the transported cargo. In rare cases, this means particles of abrasive sand between the bullet and the part, which acts as a sliding base. Due to the above factors, this occurs as a result of premature repair and improper use of roller guides.

In addition, the part, which acts as a sliding base, is the formation of radial voids as a result of wear of the friction surfaces. Since the performance of the guide roller mechanisms of the conveyor belt at mining enterprises is characterized by a high radial load, it can be assumed that there is slipping or mixed sliding of parts acting as a sliding support [16].

The rotation and loading of the designed parts in a new design mounted on a roller mechanism of a conveyor belt is determined taking into account a number of factors: 
- an alternative period of constant load flows and current cycles during operation of the conveyor belt. Therefore, the design must take into account the exact operating time of the conveyor belt;

- its level fluctuates during periods of constant load flow. The characteristic oscillation time of the continuous load current, according to experimental data, is always significantly exceeds 5 seconds. The implementation of the corresponding random process is usually compared with a step-by-step function, the values of which obey the law of normal distribution, and the time between successive changes in the values corresponds to the Poisson law. The parameters of the Poisson law are called the computational speed in the process under consideration.

- in addition to the small component of the load flow, large parts of the load fall on the conveyor belt, which causes dynamic loads on the mechanisms of the guide rollers. The characteristic period of variability of these loads does not exceed the time during which part of the load passes through the gap between the mechanisms of the guide rollers and part of the second. In fact, the exposure time of most of the transported material to the mechanisms of the roller guides of the conveyor belt is much shorter.

- in addition to repairing with a vibration contact of a part that acts as a sliding base on which roller mechanisms of a conveyor belt are mounted, there are also types of abrasive and friction repairs.

This type of surface wear is preferred for parts that act as the sliding base of roller conveyor mechanisms operating on the conveyor [17].

These types of wear determine the technical source of the part, which serves as a sliding base. The reason for this phenomenon is the low quality of the protective rollers and sealing elements of the guide roller mechanism. However, the mechanisms of the roller guides of the conveyor belt are such a massive product that, perhaps, the cost savings on the protective coating elements are justified, therefore it is necessary to take into account the type of wear that is not typical for parts that serve as a sliding base [18].

\section{RESULTS AND DISCUSSION}

Many factors are known for the quick repair of parts that act as a sliding support in the guide roller mechanism. For example, studies have shown that quartz particles enter the bearing assembly as a result of wear on the protective caps. In these cases, it is observed that the service life of the guide roller mechanisms is often 350-600 hours. It is characterized by the amount of abrasive dust accumulated in the oil, and not by the number of revolutions of the guide roller mechanisms as a result of increased levels of dust and moisture. Oil dust is expressed as a percentage of the mass of dust particles in the oil (\%). In addition, a regression dependence of the dustiness of the oil on the test time is given:

$$
m=p t^{u} M^{K}, \%
$$

Where $t$ - is time, hour; $M$ - air dust, $\mathrm{kg} / \mathrm{m}^{3}, \mathrm{p}, \mathrm{u}, \mathrm{k}$ empirical constants that depend on the structural characteristics of the part, which acts as a sliding base.

The radial clearance of the inner surface of the part, acting as a sliding base, is determined by the following formula.

$$
\Delta=\delta_{0}+12.23 \cdot 10^{-6} \mathrm{~m}
$$

Where $\delta_{0}-$ is the initial working radial clearance for parts with an inner diameter of $d=30 \mathrm{~mm}, \delta_{0} \approx 10 \mathrm{mkm}$ is a test sliding base with a load of $100 \mathrm{~N}$. Environmental dust $M: M=(0.5-3.4) \cdot 10^{-3} \mathrm{~kg} / \mathrm{m}^{3}$

In this case, abrasive wear of the friction surface of the part serving as a sliding base (crack) is often observed.

If we generalize formulas (1) and (2), and in experimental studies take into account the rotation speed of differential roller mechanisms, we obtain (3).

$$
\Delta \cong \delta_{0}+\frac{12.23 \cdot 10^{-6}(1+d / 8)}{700^{u} \cdot 4.75} p t^{u} M^{k} n^{u}
$$

However, in experimental studies, it is taken into account that the mechanisms of the guide rollers, which coincide with the actual parts used in the production environment, are carried out at rotational speeds, and that the contaminants entering through the protective caps are closely related to the rotational speed [19].

However, given that graphitecaprolon material is a solid, corrosion-resistant and brittle material, we cover it with a sleeve of material with a flexible element on the outside and design a new type of roller mechanism. When designing a roller mechanism consists of creating a mechanism with a large weight and low strength, as well as creating relatively optimal options for the details of the mechanism. To do this, we will study several types of plastic and rubber grades and choose the material grade with the highest strength. Of course, we must take into account the chemical, physical and mechanical properties of these materials [20].

It is important to determine the frequency of vibrations of the plastic grates, which affect the cleaning effect. For an approximate determination of the deformation value of the supports of the grate, we consider the kinetic energy of the pulled support roller, together with the grate, during the impact, passing into the potential energy of the deformable rubber support:

$$
T=\frac{m v_{y}^{2}}{2} ; P=\int_{0}^{x_{\max }}\left(c_{1} x+c_{2} x^{3}\right) d x
$$

where: $T$ - kinetic energy of the roller support and grate; $m$ - is the total mass of the grate and roller support; $v_{y}$ - the speed of impact of the roller on the grate; $c_{1}$ - linear component of the stiffness coefficient of the elastic support; $c=\frac{c_{2}}{\mu}-$ the 
nonlinear component of the stiffness coefficient; $\mathrm{P}$ is the potential energy of the deformable elastic support; $\mathrm{P}$ - from the accepted interaction conditions:

$$
v_{y}=\sqrt{\frac{2}{m} \int_{0}^{a} c_{1} x d x+\int_{0}^{a} \frac{c_{2}}{\mu} x^{3} d x}
$$

Where, $a-$ is the maximum strain value.

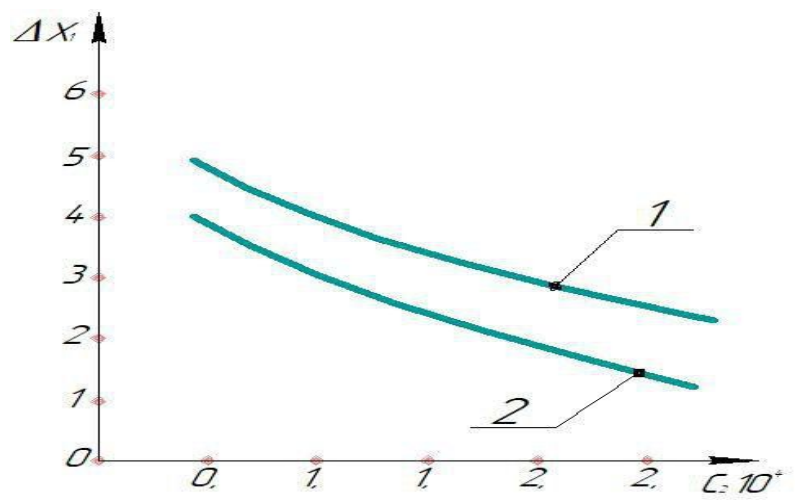

1-for $\omega=65 s^{-1} 2$ - for $\omega=40 s^{-1}$,

$c_{1}=1.5 \cdot 10^{4} \mathrm{~N} / \mathrm{m}, m=1.20 \mathrm{Ns}^{2} / \mathrm{m}$

Figure 6: Dependences of the change in the range of vibrations of the plastic grate as a function of the stiffness coefficient of the elastic support of the roller cleaner

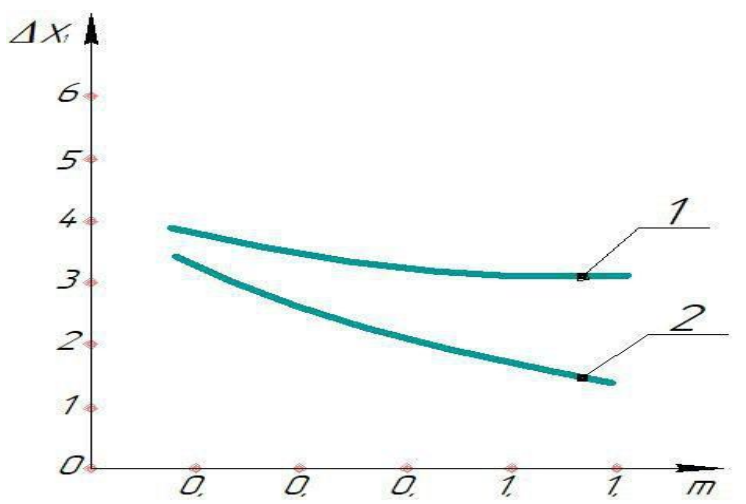

1-for $\omega=65 s^{-1} 2$ - for $\omega=40 s^{-1}$

Figure 7: Dependences of the change in the range of vibrations of the plastic grate depending on its mass

According to studies, with nonlinear rigidity of the elastic element, a single mass vibration system of the plastic grate of the system under conditions from $x=0$ to $x=0$ will

$$
t=4 \sqrt{\frac{n}{a}} \cdot \frac{1}{a^{n-1}} \int_{0}^{1} \frac{d \xi}{\sqrt{1-\xi^{2 n}}}
$$

Where, $a$ and $n$ are constants, $n-1,2, \ldots \ldots, ; \xi=\frac{X}{a}$ when the restoring force is equals $a x^{2 n-1}$.

In oscillatory systems with nonlinear rigidity of the elastic element, there is a definite relationship between the period and the amplitude. For this reason, with the use of such systems, the term "natural frequency" is also avoided, since the frequency of free vibrations ceases to be the system's own parameter. In this case, the recovering force $c_{1} x+\frac{c_{2}}{\mu} x^{3}$ and therefore the value take the values 1 and 2 . Then the period of oscillation of the plastic grate on an elastic support with nonlinear rigidity is determined from the expression:

$$
t=4 \sqrt{m}\left[\sqrt{\frac{1}{c_{1}}} \int_{0}^{1} \frac{d \xi}{\sqrt{1-\xi^{2 n}}}+\sqrt{\frac{2 \mu}{c_{1} a^{2}}} \int_{0}^{1} \frac{d \xi}{\sqrt{1-\xi^{4}}}\right]
$$

Where, $\mu$ is a coefficient taking into account the nonlinearity of the elastic characteristic, $\mathrm{m}^{2}$.

In the resulting expression (1.3), we integrate the terms in brackets, while the second term is calculated (integrated) using tables of special functions according to the work and we obtain

$$
t_{k}=4 \sqrt{m}\left[6.28 \frac{1}{c_{1}}+\frac{1.8541}{a \sqrt{c_{2}^{2} / \mu}}\right]
$$

For the frequency of free oscillations, taking into account $\rho_{k}=\frac{2 \pi}{T}$, we have:

$$
\rho_{k}=\frac{0.25 a \sqrt{c_{1} c_{1} / \mu}}{\sqrt{m}\left(2 \pi a \sqrt{c_{2} / \mu}+1.85 \sqrt{c_{1}}\right)}
$$

An analysis of the derived formula (1.6) shows that the natural oscillation frequency nonlinearly decreases with an increase in the reduced mass of the plastic grate from the roller. With an increase in the amplitude of oscillations and stiffness coefficients $c_{1}$ and $c_{2}$ the frequency of natural oscillations changes in a nonlinear dependence. It is important to ensure the vibrations of the grid-iron in the pre-resonance zone, since the natural frequency of vibrations of the grid-iron also varies depending on the values of reduced mass, amplitude, and also the nonlinear stiffness characteristic of the elastic support. In numerical calculations, the initial parameters are taken: Fig. 8 graphical dependences of the change in the relative value of the natural frequency of oscillations of the plastic grate from the increase in its reduced mass are given. Analysis of the graphs shows that the relative value of the natural frequency with an increase in the reduced mass of the grate is reduced by a nonlinear regularity. The magnitude of the amplitude (deformation of the elastic support) does not actually affect this regularity, i.e., an increase in the amplitude leads to a parallel upward movement of the regularity curve with the difference $\rho_{k} / \rho_{H}=0.25-0.05$ (with increasing a from $0.8 \cdot 10^{-3} \mathrm{~m}$ to $1.2 \cdot 10^{-3} \mathrm{~m}$ ). In this case, the average 
Anvar Djuraev et al., International Journal of Emerging Trends in Engineering Research, 8(9), September 2020, 6609 - 6617

weight of the roller on average located on the surface of the grate is included in the mass of the plastic grate.

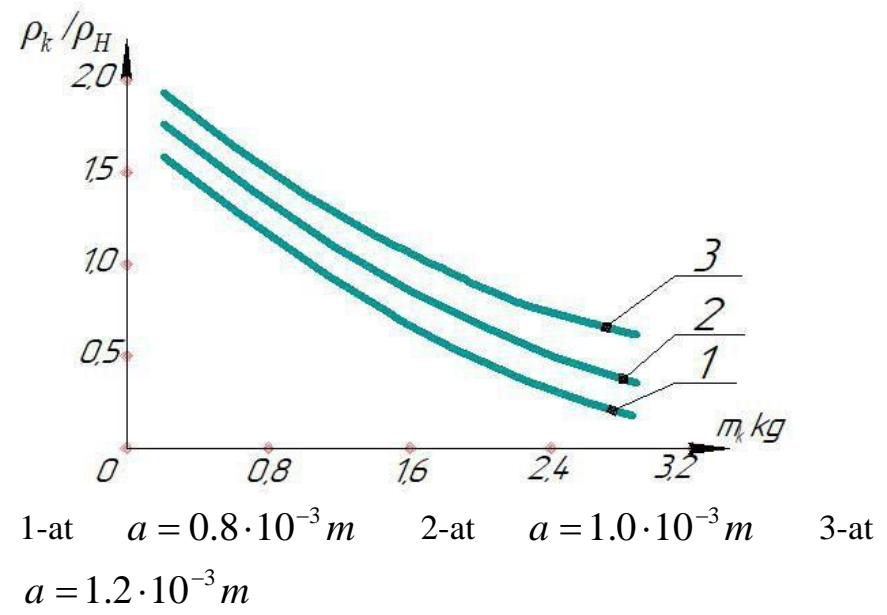

Figure 8: Graphic dependences of the changed relative value of the natural frequency of vibrations of the plastic grate from an increase in its reduced mass

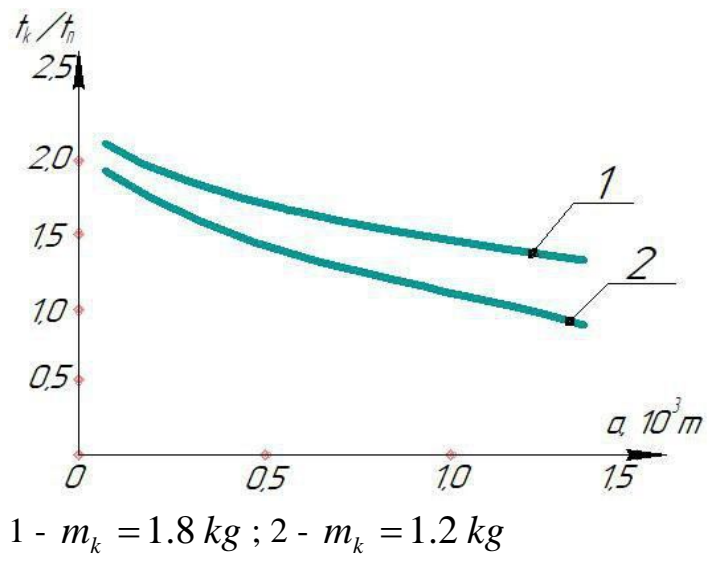

Figure 9: Graphic dependences of the change in the relative value of the period of oscillation of the plastic grate from the change in maximum amplitude

It should be noted that the plastic grid-irons actually make complex vibrations. Grid-irons will actually make vertical vibrations. Taking into account the random function of the disturbing force from the support roller, the nonlinearity of the restoring force of the elastic support, its dissipative characteristics, taking into account the work, we can write the equation of the oscillatory motion of the grate in the form:

$$
m \frac{d^{2} x}{d t^{2}}+b \frac{d x}{d t}+c_{1} x+\frac{c_{2}}{\mu} x^{3}=M\left(F_{b}\right) \pm \delta\left(F_{b}\right)
$$

Where, $b$ is the coefficient of internal resistance of the elastic support of the grate. Solution by analytical methods presents a certain difficulty. The solution can be carried out by approximate methods. To conduct a machine experiment, we solve the problem by a numerical method on a PC using standard programs. In this case, the following calculated values of the parameters were taken into account:

$$
\begin{aligned}
& m=0.8 \div 1.5 \mathrm{Ns}^{2} / \mathrm{m} ; c_{1}=(0.8 \div 1.0) \cdot 10^{4} \mathrm{~N} / \mathrm{m} \\
& c_{1}=(1.2 \div 1.4) \cdot 10^{4} \mathrm{~N} / \mathrm{m}, b=50 \div 60 \mathrm{Ns} / \mathrm{m}, \\
& \mu=1.0 \mathrm{~m}^{2}
\end{aligned}
$$

To determine the best dynamic parameters of conical grates on elastic supports with non-linear stiffness, taking into account the randomness of technological disturbances from the roller, the following variations of the parameters were carried out.

a) The mass of the grate is appropriate to reduce the mass of the grate. This reduces the consumption of metal, and also increases the possibility of oscillations with the required amplitude. The mass variation of the lightweight plastic grate is carried out in the range, $m=0.8 \div 1.5 \mathrm{Ns}^{2} / \mathrm{m}$.

b) The stiffness coefficients of the elastic supports. As noted above, the dependence of the strain on the load of the elastic support (rubber sleeve) is non-linearly rigid, that is, with increasing load, the intensity of the increase in strain decreases.

In this case, the stiffness coefficients (the thickness of the rubber bushings vary) varied within the limits, $c_{1}=(1.0 \div 1.2) \cdot 10^{4} \mathrm{~N} / \mathrm{m}$ and $c_{2}=(1.2 \div 1.4) \cdot 10^{4} \mathrm{~N} / \mathrm{m}$. In this case, the coefficient of nonlinearity of the stiffness characteristic is assumed to be constant.

c) The dissipation coefficient of the elastic support of the plastic grate. For each type (brand) of rubber, the coefficient of internal friction has different values. The dissipation coefficient of the elastic support characterizes the attenuation rate of the natural vibrations of the plastic grate. Given that the natural oscillation frequency of the great varies depending on the amplitude of the oscillations, it is advisable to quickly damp the natural oscillations. For applicable grades (HO-681338, 1343) of rubber, taking into account the conditions of their operation (low-frequency mode), the dissipation coefficient will be varied within, $b=50 \div 60 \mathrm{Ns} / \mathrm{m}$

d) Disturbing force - the technological load on the conical grate from raw cotton. This power is mainly dependent on the performance of the machine. With the productivity of the UHK cotton cleaner $P_{r}=6.0 \mathrm{t} / \mathrm{h}$ the technological load on the grate will be $M\left(F_{b}\right)=(19.7 \pm 0.9) \mathrm{N}$

Consideration of the technological load from the roller on lightweight plastic grates is due to the fact that their value during the cleaning process is random in nature, which actually forms the vibration of the conical grate. The nature and magnitude of the technological resistance force were determined experimentally by the method of strain gauging. From the analysis of the experimental data and their processing by the method of mathematical statistics, the mathematical expectation of the perturbation force from the roller to the grate and its possible variations both in frequency and amplitude were determined. To study the forced 
Anvar Djuraev et al., International Journal of Emerging Trends in Engineering Research, 8(9), September 2020, 6609 - 6617

vibrations of plastic grates on elastic supports with non-linear characteristics, a PC implementation algorithm was compiled, which included taking into account the random process load from the roller in the form of a random number generator with a frequency of $50 \mathrm{~Hz}$ and an amplitude of $18 \mathrm{~N}$. As a result of the implementation of the mathematical model of the oscillatory system of the grate of the roller from large rubbish on a PC with variations in the parameters, graphical dependencies are obtained.

A fragment of displacement, speed, and acceleration of a conical grate on an elastic support with a nonlinear restoring force at $m=1.0 \frac{N s^{2}}{m} \quad$ and $\quad c_{1}=0.8 \cdot 10^{4} \mathrm{~N} / \mathrm{m}$, $c_{1}=1.2 \cdot 10^{4} \mathrm{~N} / \mathrm{m}, M\left(F_{b}\right)=10.5 \mathrm{~N}, \delta F_{b}=(0.7 \div 1.0) \mathrm{N}$ It should be noted that the grate oscillation frequency is (40-55) $\mathrm{Hz}$. In this case, the high-frequency component of the great oscillations is (147-178) $\mathrm{Hz}$.

For metal grates on elastic supports according to the work, the amplitude of the oscillations is $\Delta X=(2.2 \div 2.5) \cdot 10^{3} \mathrm{~m}$ Comparison of the results shows that in the proposed design of the plastic grate, the amplitude of vibrations increases by $(10 \div 15) \%$ due to the lightweight construction of the grate.

\section{CONCLUSION}

The operating conditions and characteristics of the conveyor belts of mining enterprises were examined, and special requirements for the design of their main components were established. Designs of roller mechanisms of the conveyor belt, parts and protective casing and sealing devices that act as a sliding base, developed on the basis of structural solutions, have been developed. Many factors were analyzed for the quick repair of parts that act as a sliding bearing in the guide roller mechanism.

\section{REFERENCES}

1. O. I. Rajabov, A. S. Abrorov, N. I. Mirzaqulova, G. B. Zaripov, Kh. S. Ziyodullaev, An experimental study of the location of the grid bars cells installed under spiked cylinders in a cotton cleaner from small waste, IOP Conference Series: Materials Science and Engineering, (2020), 734(1) 012073.

2. O.I. Rajabov, F.A.Fazliddin, M. H. Gapparova and J. Shakhrillo, The influence of the location of the cells on the allocation of weed impurities for cleaning raw cotton from fine waste, IOP Conference Series: Materials Science and Engineering, (2020), 734(1) 012073.

3. Murodov $\mathrm{O}$, Perfection of designs and rationale of parameters of plastic koloski cleaning cleaners, International Journal of Innovative Technology and Exploring Engineering, vol. 8, No 12, (2019), pp.
26401-2646.

4. Juraev Anvar and Rajabov Ozod, Analysis of the interaction of Fibrous Material with a Multifaceted Grid of the cleaner, International Journal of Recent Technology and Engineering, vol. 8, No 1, (2019), pp. 2661-2666.

5. Djuraev Anvar and Kuliev Tokhir Mamarajapovich, Designing and Methods of Calculating Parameters of a Fibrous Material Cleaner From Large Litter, International Journal of Advanced Science and Technology, Vol. 29, No. 8s, (2020), pp. 444-452.

6. Djuraev Anvar and Kuliev Tokhir Mamarajapovich, Improvement of the Construction and Justification of Parameters of the Fibrous Material Regenerator, International Journal of Advanced Science and Technology, Vol. 29, No. 8s, (2020), pp. 453-460.

7. Rajabov O, Fazliddin K, and Salimov Sh., Substantiation of Parameters of the Fibrous Material Cleaning Zone, International Journal of Engineering and Advanced Technology, vol. 9, No 3, (2020), pp. 1052-1057.

8. Akbar Abrorov, Matluba Kuvoncheva, Ozod Rajabov, Mukhsin Mukhammadov and Shakhrillo Jumaev, Method of thermal treatment of saw disk teeth of fiber-processing machines by laser quenching, IOP Conference Series: Materials Science and Engineering, (2020), 862032034.

9. Jurayev A., and Rajabov O., Experimental study of the interactional of multifaceted and cylindrical spiky cylinder in cotton cleaner from small waste, International Journal of Advanced Research in Science, Engineering and Technology. Vol. 6, Issue 3, (2019). pp. 8376-8381.

10. Rajabov Ozod Isroilovich, The influence of the mode of movement of the pieces cotton when interacting with a cotton grid, International Journal of Advanced Research in Science, Engineering and Technology (India). Vol. 6, Issue 3, (2019). pp. 8455-8381.

11. Ozod Rajabov and Ziyodullo Shodiyev, Analysis of Small Fluctuations of a Multifaceted Mesh under the Influence of Technological Load from the Cleaned Cotton - Raw, International Journal of Advanced Research in Science, Engineering and Technology, Vol. 6, Issue 10, (2019), pp. 11396-11399.

12. Bekhruz Gaybulloev, Nigina Ergasheva, Ozod Rajabov, The Structure of the Embroidery Machine and Dynamic Analysis of the Needle Mechanism, International Journal of Advanced Research in Science, Engineering and Technology, Vol. 7, Issue 1, (2020). pp. 8376-8381.

13. Anvar Djuraev and Ozod Isroilovich Rajabov, Substantiation of the main parameters of the cylinder with multifaceted spiked of the cotton cleaner from small waste, International scientific and practical conference Innovative ideas of modern youth in science, (2019), USA. pp. 149-151

14. Smirnova Zhanna.V, Vaganova O.I., Chaykina Zh. V., Golubeva O.V. Calculation of metallurgical processes 
during welding, International Journal of Emerging Trends in Engineering Research, Volume 8. No. 5, May 2020, pp. 1529-1534

15. A.M.Mahaboob Basha, M.Rajaiah, P.Penchalaiah, CH.Raja Kamal, B.Niranjana Rao. Machine Learning-Structural Equation Modeling Algorithm: The Moderating role of Loyalty on Customer Retention towards Online Shopping, International Journal of Emerging Trends in Engineering Research, Volume 8. No. 5, May 2020, pp. 1578-1585

16.

17. Mavlyanov Aybek Palvanbaevich, Rajabov Ozod Isroilovich and Yakubova Aziza Vakil qizi, Study of the influence of the parameters of the plastic grate on elastic supports with nonlinear stiffness on the oscillation frequency, International scientific and practical conference Innovative ideas of modern youth in science, (2019), USA. P. 152-154

18. A.Djuraev, Sh. S. Khudaykulov, A. S. Jumaev Development of the Design and Calculation of Parameters of the Saw Cylinder with an Elastic Bearing Support Jin. 'International Journal of Recent Technology and Engineering
(IJRTE), ISSN: 2277-3878, Volume 8 Issue 5, January 2020. pp. 4842-4847.

19. Djuraev A.D , Jumaev A.S. Study the influence of parameters of elastic coupling on the movement nature of support roller and rocker arm crank-beam mechanism. International Journal of Advanced Research in Science, Engineering and Technology, Vol. 6, Issue 6 , June 2019 Copyright to IJARSET www.ijarset.com 9795.

20. Ozod Rajabov, Ziyodullo Shodiyev, Ikrom Inoyatov, Mastura Gapparova. Analysis of the Technological Process of Cleaning Raw Cotton from Small Trash, International Journal of Emerging Trends in Engineering Research, Volume 8. No. 9, September 2020, pp. 6022-6029 